\section{JURNAL EKONOMI EFEKTIF}

ISSN : $2622-8882$, E-ISSN : 2622-9935

Jurnal Ekonomi Efektif, Vol. 3, No. 2, Januari 2021 @Prodi Manajemen Fakultas Ekonomi Universitas Pamulang

\title{
PENGARUH PERPUTARAN MODAL KERJA TERHADAP PROFITABILITAS PADA PT. ANABATIC TECHNOLOGIES TBK PERIODE 2012-2019
}

\author{
Ria Rosalia Simangunsong \\ Universitas Pamulang, Tangerang Selatan, Banten, Indonesia \\ dosen02511@unpam.ac.id
}

Manuskrip: Nov-2020; Ditinjau: Des-2020; Diterima: Des-2020; Online: Jan-2021; Diterbitkan: Jan-2021

\begin{abstract}
ABSTRAK
Penelitian ini bertujuan untuk mengetahui pengaruh Perputaran modal kerja terhadap Profitabilitas pada PT. Anabatic Technologies Tbk. Metode yang digunakan adalah explanatory research. Teknik analisis menggunakan analisis statistik dengan pengujian regresi, korelasi, determinasi dan uji hipotesis. Hasil penelitian ini variabel Perputaran modal kerja diperoleh nilai rata-rata sebesar 3,552\%. Variabel Profitabilitas diperoleh nilai rata-rata $8,380 \%$. Perputaran modal kerja berpengaruh positif dan signifikan terhadap Profitabilitas dengan nilai persamaan regresi $\mathrm{Y}=1,311+0,002 \mathrm{X}$, dan nilai koefisien korelasi 0,724 atau memiliki tingkat hubungan yang kuat dengan nilai determinasi 52,4\%. Uji hipotesis diperoleh signifikansi $0,000<0,05$.
\end{abstract}

\section{Kata Kunci: Perputaran Modal Kerja, Profitabilitas.}

\section{ABSTRACT}

This study aims to determine the effect of working capital turnover on profitability at PT. Anabatic Technologies Tbk. The method used is explanatory research. The analysis technique uses statistical analysis with regression testing, correlation, determination and hypothesis testing. The results of this study the variable working capital turnover obtained an average value of $3.552 \%$. The profitability variable obtained an average value of $8.380 \%$. Turnover of working capital has a positive and significant effect on profitability with the regression equation $Y=1.311+0.002 X$, and a correlation coefficient value of 0.724 or has a strong level of relationship with a determination value of $52.4 \%$. Hypothesis testing obtained a significance of $0.000<0.0$.

Keywords: Working Capital Turnover, Profitability. 


\section{PENDAHULUAN}

\section{A. Latar Belakang Masalah}

Setiap perusahaan dalam menjalankan operasinya selalu diarahkan pada pencapaian tujuan yang telah ditetapkan. Tujuan utama didirikan perusahaan adalah untuk memaksimalkan kekayaan pemegang saham. Salah satu cara untuk mencapai tujuan perusahaan adalah dengan meningkatkan profitabilitas perusahaan tersebut. Profitabilitas menunjukkan keunggulan perusahaan dalam persaingan bisnis. Semakin tinggi tingkat profitabilitas maka kinerja perusahaan semakin baik.

Profitabilitas adalah kemampuan perusahaan memperoleh laba dalam hubungannya dengan penjualan, total aktiva maupun modal sendiri (Sartono, 2010:122). Bagi perusahaan masalah profitabilitas sangat penting. Bagi pimpinan perusahaan, profitabilitas digunakan sebagai tolak ukur berhasil atau tidak perusahaan yang dipimpinnya. Sedangkan bagi karyawan perusahaan, semakin tinggi profitabilitas yang diperoleh perusahaan, maka ada peluang untuk meningkatkan gaji karyawan. Profitabilitas yang tinggi akan dapat mendukung kegiatan operasional secara maksimal. Tinggi rendahnya profitabilitas dipengaruhi banyak faktor seperti modal kerja.

Modal kerja adalah investasi perusahaan jangka pendek seperti kas, surat berharga, piutang dan inventori atau seluruh aktiva lancar (Putra, 2012). Mengingat pentingnya modal kerja dalam perusahaan, manajer keuangan harus dapat merencanakan dengan baik besarnya jumlah modal kerja yang tepat dan sesuai dengan kebutuhan perusahaan, karena jika terjadi kelebihan atau kekurangan dana hal ini akan mempengaruhi tingkat profitabiltas perusahaan (Supriyadi dan Fazriani, 2011).

Jika perusahaan kelebihan modal kerja akan menyebabkan banyak dana yang menganggur, sehingga dapat memperkecil profitabilitas. Sedangkan apabila kekurangan modal kerja, maka akan menghambat kegiatan operasional perusahaan. Adapun tiga komponen modal kerja yaitu kas, piutang, dan persediaan. Ketiga komponen modal kerja tersebut dapat dikelola dengan cara yang berbeda untuk memaksimalkan profitabilitas atau untuk meningkatkan pertumbuhan perusahaan (Lazaridis dan Tryfonidis, 2010).

Pengelolaan modal kerja sangat penting karena menyangkut penetapan kebijakan modal kerja maupun pelaksanaan kebijakan modal kerja tersebut dalam operasi seharihari. Manajemen modal kerja berkepentingan terhadap keputusan investasi pada aktiva lancar dan hutang lancar. Terutama mengenai bagaimana menggunakan dan kompisisi keduanya akan mempengaruhi resiko, Weston dan Brigham (1981:245) menjelaskan bahwa manajemen modal kerja adalah investasi perusahaan dalam jangka pendek terdiri dari empat komponen utama yaitu kas, surat-surat berharga (efek), persediaan dan piutang usaha. Dengan modal kerja operasi perusahaan akan berjalan ekonomis dan efisien.

Jumlah keuntungan yang diperoleh secara teratur merupakan salah satu faktor yang penting untuk menilai profitabilitas. Profitabilitas merupakan kemampuan perusahaan untuk menghasilkan laba dalam hubungan penjualan, total aktiva maupun modal sendiri sering digunakan untuk mengatur efisiensi penggunaan modal suatu perusahaan dengan memperbandingkan antara laba dengan modal yang digunakan dalam operasi, oleh karena itu keuntungan yang besar tidak menjamin atau bukan merupakan ukuran bahwa dalam perusahaan tersebut dapat melangsungkan hidupnya secara kontinu. Bagi perusahaan pada umumnya masalah rentabilitas lebih penting daripada profit, karena profit yang besar saja belum merupakan ukuran bahwa perusahaan tersebut telah bekerja dengan efisien. Efisien baru dapat diketahui dengan membandingkan laba yang diperoleh dengan kekayaan atau modal yang menghasilkan profit. Oleh karena itu profitabilitas merupakan pencerminan dari efisiensi. Dengan demikian yang harus diperhatikan oleh 
perusahaan adalah tidak hanya bagaimana usaha untuk memperbesar profit, tetapi yang lebih penting adalah usaha untuk mempertinggi profitabilitasnya.

Penelitian menunjukkan bahwa penambahan modal kerja tidak selalu dapat menaikkan rentabiilitas perusahaan, dilihat dari pengaruh perubahan modal kerja terhadap Gross Profit Margin (GPM), Net Profit Margin (NPM), Net Earning Power Ratio (Rate of Return on Investment/ROI), Rate of Return The Owners (Rate or Return on Equity/ROE).

Berdasarkan kondisi yang telah dipaparakan, penulis tertarik untuk meneliti dan menganalisa pengaruh perubahan Modal Kerja Bersih pada PT. Anabatic Technologies Tbk. Penelitian dan analisa ini di kembangkan dalam bentuk skripsi yang berjudul "Pengaruh Perputaran Modal Kerja Terhadap Profitabilitas PT. Anabatic Technologies Tbk.".

\section{B. Rumusan Masalah}

1. Bagaimana Perputaran modal kerja pada pada PT. Anabatic Technologies Tbk?.

2. Bagaimana Profitabilitas pada PT. Anabatic Technologies Tbk?.

3. Adakah pengaruh antara Perputaran modal kerja terhadap Profitabilitas pada PT. Anabatic Technologies Tbk?.

\section{Tujuan Penelitian}

1. Untuk mengetahui kondisi Perputaran modal kerja pada PT. Anabatic Technologies Tbk.

2. Untuk mengetahui kondisi Profitabilitas pada PT. Anabatic Technologies Tbk.

3. Untuk mengetahui pengaruh antara Perputaran modal kerja terhadap Profitabilitas pada PT. Anabatic Technologies Tbk

\section{METODE PENELITIAN}

\section{Populasi}

Populasi dalam penelitian ini laporan keuangan PT. Anabatic Technologies Tbk selama 8 tahun

\section{Sampel}

Teknik pengambilan sampling dalam penelitian ini adalah samplel jenuh, dimana semua anggota populasi dijadikan sebagai sampel. Dengan demikian sampel dalam penelitian ini laporan keuangan PT. Anabatic Technologies Tbk selama 8 tahun.

\section{Jenis Penelitian}

Jenis penelitian yang dipakai adalah asosiatif, dimana tujuannya adalah untuk mengetahui mencari keterhubungan antara variabel independen terhadap variabel dependennya

\section{Metode Analisis Data}

Dalam menganalisis data digunakan uji validitas, uji reliabilitas, analisis regresi linier sederhana, koefisien korelasi, koefisien determinasi dan uji hipotesis.

\section{HASIL PENELITIAN DAN PEMBAHASAN}

\section{Analisis Deskriptif}

Pada pengujian ini digunakan untuk mengetahui skor minimum dan maksimum skor tertinggi, ratting score dan standar deviasi dari masing-masing variabel. Adapun hasilnya sebagai berikut: 
Tabel 1. Hasil Analisis Descriptive Statistics

Descriptive Statistics

\begin{tabular}{|lr|r|r|r|r|} 
& N & Minimum & Maximum & Mean & Std. Deviation \\
\hline Perputaran modal kerja (X) & 8 & 3101.2 & 4547.3 & 3522.36 & 537.0497 \\
\hline Profitabilitas (Y) & 8 & 6.4 & 10.9 & 8.380 & 1.4888 \\
\hline Valid N (listwise) & 8 & & & & \\
\hline
\end{tabular}

Perputaran modal kerja diperoleh nilai minimum sebesar 3.101 dan nilai maximum 4.547 dengan rata-rata sebesar 3,552 dengan standar deviasi 537,049. Profitabilitas diperoleh nilai minimum sebesar 6,4 dan nilai maximum 10,9 dengan rata-rata sebesar 8,380 dengan standar deviasi 1,488 .

\section{Analisis Verifikatif.}

Pada analisis ini dimaksudkan untuk mengetahui pengaruh variabel independen terhadap variabel dependen. Adapun hasil pengujian sebagai berikut:

\section{a. Analisis Regresi Linier Sederhana}

Uji regresi ini dimaksudkan untuk mengetahui perubahan variabel dependen jika variabel independen mengalami perubahan. Adapun hasil pengujiannya sebagai berikut:

\begin{tabular}{|c|c|c|c|c|c|}
\hline \multirow[b]{3}{*}{ Model } & \multicolumn{2}{|c|}{ Coefficients $^{\mathrm{a}}$} & \multirow[b]{2}{*}{$\begin{array}{l}\text { Standardized } \\
\text { Coefficients }\end{array}$} & \multirow[b]{3}{*}{$\mathrm{t}$} & \multirow[b]{3}{*}{ Sig. } \\
\hline & \multicolumn{2}{|c|}{$\begin{array}{l}\text { Unstandardized } \\
\text { Coefficients }\end{array}$} & & & \\
\hline & B & Std. Error & Beta & & \\
\hline 1 (Constant) & 1.311 & 2.778 & & .472 & .654 \\
\hline Perputaran modal kerja $(\mathrm{X})$ & .002 & .001 & .724 & 2.570 & .042 \\
\hline
\end{tabular}

Berdasarkan hasil pengujian pada tabel di atas, diperoleh persamaan regresi $\mathrm{Y}$ $=1,311+0,002 X$. Dari persamaan tersebut dijelaskan sebagai berikut:

1) Konstanta sebesar 1,311 diartikan jika Perputaran modal kerja tidak ada, maka telah terdapat nilai Profitabilitas sebesar 1,311 point.

2) Koefisien regresi Perputaran modal kerja sebesar 0,002, angka ini positif artinya setiap ada peningkatan Perputaran modal kerja sebesar 0,002 point maka Profitabilitas juga akan mengalami peningkatan sebesar 0,002 point.

\section{b. Analisis Koefisien Korelasi}

Analisis koefisien korelasi dimaksudkan untuk mengetahui tingkt kekuatan hubungan dari variabel independen terhadap variabel dependen baik secara parsial maupun simultan. Adapun hasil pengujian sebagai berikut:

Tabel 3. Hasil Pengujian Koefisien Korelasi Perputaran modal kerja Terhadap Profitabilitas..

\section{Correlations $^{\text {b }}$}

\begin{tabular}{llr|r} 
& & $\begin{array}{c}\text { Perputaran modal kerja } \\
\text { (X1) }\end{array}$ & Profitabilitas (Y) \\
\hline $\begin{array}{l}\text { Perputaran modal } \\
\text { kerja (X) }\end{array}$ & Pearson Correlation & 1 & $.724^{*}$ \\
\cline { 2 - 4 } Profitabilitas (Y) & Sig. (2-tailed) & & .042 \\
\hline & Pearson Correlation & $.724^{*}$ & 1 \\
\cline { 2 - 4 } & Sig. (2-tailed) & .042 & \\
\hline
\end{tabular}

Berdasarkan hasil pengujian diperoleh nilai korelasi sebesar 0,724 artinya

Perputaran modal kerja memiliki hubungan yang kuat terhadap Profitabilitas. 


\section{c. Analisis Koefisien Determinasi}

Analisis koefisien determinasi dimaksudkan untuk mengetahui besarnya persentase pengaruh dari variabel independen terhadap variabel dependen. Adapun hasil pengujian sebagai berikut:

Tabel 4. Hasil Pengujian Koefisien Determinasi Perputaran modal kerja Terhadap

Profitabilitas.

Model Summary

\begin{tabular}{lc|r|r|r} 
Model & R & R Square & Adjusted R Square & Std. Error of the Estimate \\
\hline 1 & $.724^{\mathrm{a}}$ & .524 & .445 & 1.1095 \\
\hline
\end{tabular}

Berdasarkan hasil pengujian diperoleh nilai determinasi sebesar 0,524 artinya Perputaran modal kerja memiliki kontribusi pengaruh sebesar 52,4\% terhadap Profitabilitas.

\section{d. Uji Hipotesis}

Pengujian hipotesis dengan uji t digunakan untuk mengetahui hipotesis mana yang diterima. Rumusan hipotesis: Terdapat pengaruh yang signifikan antara Perputaran modal kerja terhadap Profitabilitas.

Tabel 5. Hasil Uji Hipotesis Perputaran modal kerja Terhadap Profitabilitas.

\section{Coefficients $^{\mathrm{a}}$}

Unstandardized $\quad$ Standardized

Coefficients Coefficients

\begin{tabular}{|c|c|c|c|c|c|}
\hline Model & $\mathrm{B}$ & Std. Error & Beta & $\mathrm{t}$ & Sig. \\
\hline 1 (Constant) & 1.311 & 2.778 & & .472 & .654 \\
\hline Perputaran modal kerja (X) & .002 & .001 & .724 & 2.570 & .042 \\
\hline
\end{tabular}

Berdasarkan hasil pengujian pada tabel di atas, diperoleh nilai t hitung $>\mathrm{t}$ tabel atau $(2,570>2,447)$, dengan demikian hipotesis yang diajukan bahwa terdapat pengaruh yang signifikan atara Perputaran modal kerja terhadap Profitabilitas diterima.

\section{PEMBAHASAN HASIL PENELITIAN}

\section{Kondisi Jawaban Responden Variabel Perputaran modal kerja}

Berdasarkan data empiris dan analisis data, variabel Perputaran modal kerja diperoleh nilai rata-rata per tahun sebesar 3,552\%.

\section{Kondisi Jawaban Responden Variabel Kinerja Karyawan}

Berdasarkan data empiris dan analisis data, variabel Profitabilitas diperoleh nilai rata-rata per tahun sebesar $8,380 \%$.

\section{Pengaruh Motivasi Terhadap Kinerja Karyawan}

Perputaran modal kerja berpengaruh signifikan terhadap Profitabilitas dengan persamaan regresi $\mathrm{Y}=1,311+0,002 \mathrm{X}$, nilai korelasi sebesar 0,724 atau memiliki hubungan yang kuat dengan kontribusi pengaruh sebesar 52,4\%. Pengujian hipotesis diperoleh nilai $t$ hitung $>\mathrm{t}$ tabel atau $(2,570>2,447)$. Dengan demikian hipotesis yang diajukan bahwa terdapat berpengaruh signifikan antara Perputaran modal kerja terhadap Profitabilitas diterima.

\section{PENUTUP}

\section{Kesimpulan}

a. Variabel Perputaran modal kerja diperoleh ratting score sebesar 3,552 berada di rentang skala 3,40-4,19 dengan kriteria baik atau setuju. 
b. Variabel Profitabilitas diperoleh ratting score sebesar 8,380 berada di rentang skala 3,40 - 4,19 dengan kriteria baik atau setuju.

c. Perputaran modal kerja berpengaruh signifikan terhadap Profitabilitas dengan persamaan regresi $\mathrm{Y}=1,311+0,002 \mathrm{X}$, nilai korelasi sebesar 0,724 atau kuat dan kontribusi pengaruh sebesar 52,4\% sedangkan sisanya sebesar 57,9\% dipengaruhi faktor lain. Uji hipotesis diperoleh nilai thitung $>\mathrm{t}$ tabel atau $(2,570>2,447)$.

\section{Saran}

a. Perkembangan perputaran modal kerja yang terdapat pada PT Anabatic Technologies Tbk cukup baik meskipun terjadi penurunan pada tahun 2018. Diharapkan untuk kedepannya perusahaan agar terus memperbaiki kinerja karyawan, penggunaan operasional perusahaan, neraca perusahaan dan L/R perusahaan.

b. Meningkatkan modal kerja secara efektif dan efisien sehingga akan lebih menguntungkan perusahaan.

c. Untuk penelitian selanjutya agar ditambahkan variabel lain agar hasil menjadi lebih baik.

\section{DAFTAR PUSTAKA}

Agus Harjito \& Martono, (2010) "Manajemen Keuangan" Yogyakarta: Penerbit Ekonisia. Agus Sartono. (2010). "Manajemen Keuangan Toeri dan Aplikasi”, Edisi keempat, Yogyakarta: Penerbit BPFE.

Algifari. (2015). “Analisis Regresi untuk Bisnis dan Ekonomi”. Yogyakarta: BPFE.

Amelia, R. W., \& Sunarsi, D. (2020). Pengaruh Return On Asset Dan Return On Equity Terhadap Debt To Equity Ratio Pada PT. Kalbe Farma, TBK. Ad Deenar: Jurnal Ekonomi dan Bisnis Islam, 4(01), 105-114.

Arikunto, Suharsimi (2014). "Prosedur Penelitian Suatu Pendekatan Praktek". Jakarta: Rineka Cipta.

Bambang Riyanto, (2011). "Dasar-dasar Pembelanjaan Perusahaan". Edisi ke empat, BPFE Yogyakarta.

Fahmi, Irham (2012), "Pengantar Manajemen Keuangan" Cetakan pertama. Bandung: Penerbit Alfabeta.

Hermanto Suaib, Joelman Subaidi, Muhammad Hatta, Sufirman Rahman, Ahmad Khoiri, (2020) Criminal Act of Drugs Abuse as Extraordinary Crime in Indonesia, International Journal of Psychosocial Rehabilitation 24 (8): 2631-2643, Doi:10.37200/IJPR/V24I8/PR280282

Hidayat, A., \& Sunarsi, D. (2020). Faktor-Faktor Yang Mempengaruhi Dana Pihak Ketiga Dan Dampaknya Terhadap Profitabilitas (Survey Pada Bpr Syariah Di Jawa Barat Tahun 2014-2017). Jurnal Proaksi, 7(1), 54-65.

Imam Ghozali (2017). “Aplikasi Analisis Multivariate Dengan Program SPSS”. Edisi Kelima. Semarang: Badan Penerbit Undip.

Istijanto (2014) "Riset Sumber Daya Manusia". Jakarta: PT. Gramedia Pustaka

Jasmani, J. (2018). Pengaruh Kinerja Keuangan Terhadap Harga Saham (Analisis Pada Perusahaan Property dan Real Estate Yang Go Public di Bursa Efek Indonesia. Jurnal Akuntansi Indonesia, 12(2).

Jasmani, J. (2019). The Effect of Liquidity and Working Capital Turnover on Profitability at PT. Sumber Cipta Multiniaga, South Jakarta. PINISI Discretion Review, 3(1), 2938.

K Nufus, H Supratikta, A Muchtar, D Sunarsi. (2020). Analysis of Financial Performance: Case Study of PT. X Employee Cooperative. Utopía Y Praxis Latinoamericana. Vol. 
25. Pages 429-444

Kasmir (2010), “Analisis Laporan keuangan”, penerbit raja grafindo persada, Jakarta

Kasmir, (2010). "Pengantar Manajemen Keuangan", Edisi Pertama, Cetakan kedua, Jakarta: Penerbit Prenada Media.

Kasmir. (2012) "Pengantar Manajemen Keuangan", Edisi Pertama, Cetakan kedua, Jakarta: Prenada Media.

Kharis, Ismu Fadli (2011). "Studi Mengenai Impulse Buying dalam Penjualan Online". Semarang : Skripsi Universitas Diponegoro

Martono dan Agus Harjito, (2011). "Manajemen Keuangan”, Jakarta: Penerbit Ekonisia..

Munawir (2010), “Analisis Laporan Keuangan”, Edisi Ke Empat, Penerbit Liberty, Yogyakarta.

Santoso, Singgih (2015). "Menguasai Statistik Multivariat". Jakarta: PT Elex Media Komputindo.

Sartono, "Manajemen Keuangan Aplikasi Dan Teori", Edisi Keempat, BPFE, Yogyakarta, 2008.

Sawir, (2003). “Analisis Kinerja Keuangan dan Perencanaan Keuangan Perusahaan”, Cetakan ketiga, Jakarta: Penerbit PT. Gramedia Pustaka Utama.

Sugiyarso, G. dan F. Winarni, "Manajemen Keuangan (Pemahaman Laporan Keuangan, Pengelolaan Aktiva, Kewajiban dan Modal serta Pengukuran

Sugiyono (2017), "Metode Penelitian Administrasi : dilengkapi dengan Metode R \& D". Bandung: Alfabeta.

Suhartono, A., Jati, W., \& Sunarsi, D. (2019). Pengaruh Earning Per Share Dan Return On Asset Terhadap Harga Saham Pada PT. Bank Negara Indonesia Tbk Periode 20092018. Jurnal Manajemen, Bisnis dan Organisasi (JUMBO), 3(3), 182-194.

Susanti, N., Latifa, I., \& Sunarsi, D. (2020). The Effects of Profitability, Leverage, and Liquidity on Financial Distress on Retail Companies Listed on Indonesian Stock Exchange. Jurnal Ilmiah Ilmu Administrasi Publik, 10(1), 45-52.

Yusni Nuryani, Denok Sunarsi. (2020). The Effect of Current Ratio and Debt to Equity Ratio on Deviding Growth. JASa (Jurnal Akuntansi, Audit dan Sistem Informasi Akuntansi) Volume 4, Issue 2, Pages 304-312. 


\section{PANDUAN SINGKAT BAGI PENULIS JURNAL EFEKTIF}

Panduan penulisan ini dimaksudkan untuk menyeragamkan bentuk penulisan karya ilmiah yang dikirim penulis ke redaksi Jurnal Efektif, dengan panduan penulisan sebagai berikut :

1. Naskah ditulis dalam Bahasa Indonesia dengan Abstrak Bahasa Indonesia dalam bentuk Font 12" dengan ukuran 1 Spasi dengan intisari tidak lebih dari 250 kata disertai 3 atau 4 kata kunci (keyword).

Naskah berupa Softcopy program MS Word maksimal 15 Halaman termasuk tabel dan gambar, spasi 1.

2. Sistematika penulisan disusun dengan urutan sebagai berikut :

a) Judul, nama dan alamat email penulis/peneliti tunggal.

b) Abstrak dan intisari, keyword dan kata kunci, dibuat dengan 1 kolom.

c) Batang Tubuh :

1). Pendahuluan, termasuk didalamnya intisari permasalahan

2). Metode Penelitian

3). Hasil dan Pembahasan

4). Kesimpulan

5). Daftar Pustaka

3. Judul ditulis dalam bentuk font Times New Roman 14" dengan huruf besar kecil dicetak tebal dan ditempatkan ditengah halaman, serta tidak lebih dari 18 kata.

4. Tulisan karya ilmiah dalam bentuk font Times New Roman 12" dengan ukuran spasi 1,0 spasi dalam bentuk normal.

5. Gambar diberi nomor dan keterangan, sedangkan tabel diberi nomor dan keterangan diatasnya sesuai dengan bab nya.

6. Penulisan persamaan matematika yang terdapat pada halaman naskah hendaknya menggunakan equation editor.

7. Daftar pustaka hanya memuat literature yang dirujuk dalam keterangan dan dicantumkan pada bagian akhir naskah.

8. Margin Normal, dan ukuran kertas A4.

Email Redaksi : denoksunarsi@ unpam.ac.id / jurnaleffective@gmail.com 